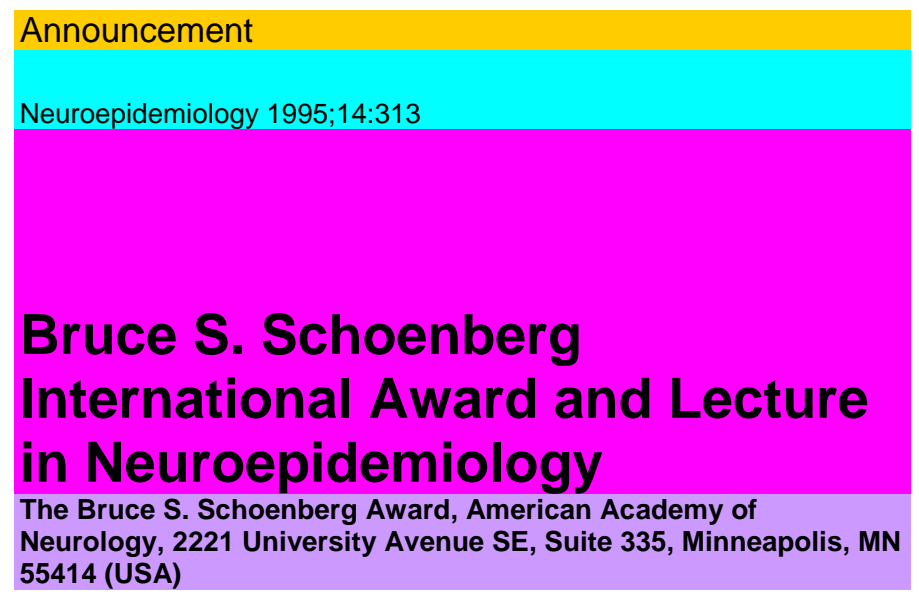

In tribute to Dr. Schoenberg's career in training neurologists internationally in epidemiologic methods, this award salutes a young investigator selected from a developing country or Eastern Europe.

Award

- Designation as recipient of the 8th Annual Bruce S. Schoenberg International Award and Lecture in Neuroepidemiology at the 48th American Academy of Neurology Annual Meeting in San Francisco, Calif.

- Recipient is expected to present a 30-min lecture, based on the selected abstract, during the Neuroepidemiology Scientific Session.

- Certificate of Recognition from the American Academy of Neurology.

- Reimbursement for travel and lodging expenses to attend the Annual Meeting.

- Complimentary admission to educational programs offered at the Annual Meeting.

Eligibility

Applicant must: be an investigator under the age of 40 ; be a permanent resident of a country outside of the United States and Canada; have participated in significant epidemiologic research in neurologic diseases, and, have collected the study data in a developing country or Eastern Europe.

\title{
Application Procedure
}

Applicant must submit ten complete, sets of the following materials: a current curriculum vitae indicating date of birth, and an extended $a b^{\wedge} \wedge S$ of up to 500 words of an epidemiologic study in which the applicant is (was) a significant participant researcher (the abstract will be ineligible for separate submission to the 1996 Scientific Program).

Deadline

All application materials must be receryed by November 13, 1995. Submit material to: 